\title{
RENAL STONE FRAGMENTS FOLLOWING SHOCK WAVE LITHOTRIPSY
}

\author{
G. ZANETTI, M. SEVESO, E. MONTANARI, A. GUARNERI, A. DEL NERO, R. NESPOLI AND \\ A. TRINCHIERI
}

From the Institute of Urology, IRCCS Ospedale Maggiore di Milano, Milan, Italy

\begin{abstract}
Purpose: We describe a select group of asymptomatic patients with fragments and dust 3 months after extracorporeal treatment, who were followed to evaluate the long-term outcome and therapeutic implications.

Materials and Methods: A total of 129 patients with dust and residual fragments (less than 4 mm.) at 3 months was re-examined at 12 months, and 95 were also evaluated at 24 months. Followup examinations consisted of radiographic studies, renal ultrasonography and urine culture. Dust and residual fragments were sought, and patients were defined as free or as having persistent lithiasis or stone regrowth. At 24 months recurrences in the patients stone-free at 12 months also were considered.

Results: At the 12-month followup 60 patients (46.5\%) were stone-free and $56(43.5 \%)$ still had dust or residual fragments. The localization of the stones or fragments at 3 months and their sizes did not have a significant influence on the stone-free rate but regrowth was greater in patients with stones larger than $10 \mathrm{~mm}$. (11 of 40 patients, $27.5 \%$ versus 2 of $89,2.2 \%, p=0.001$ ). The probability of eliminating residual lithiasis at 12 months was significantly greater in patients with dust than in those with residual fragments (42 of 79 patients, $58 \%$ versus 18 of 50 , $36 \%, \mathrm{p}=0.026$ ). Regrowth of residual lithiasis was observed in 13 patients $(10 \%)$.

Conclusions: Based on our results, we do not believe that patients with fragments require systematic re-treatment in the short term but they may be followed long term and re-treated if symptoms persist or stones recur.
\end{abstract}

KEY WORDS: extracorporeal shockwave lithotripsy, calculi

The therapeutic efficacy of shock wave lithotripsy in the treatment of renal and ureteral stones is undisputed 15 years after its introduction in clinical practice. ${ }^{1}$ This method represents a revolution in the management of patients with lithiasis. ${ }^{2}$ However, since the first large series was presented, evaluation of the results of extracorporeal treatment has been controversial. Still more controversial is the approach to patients whose stones are not completely eliminated but in whom small fragments (less than $5 \mathrm{~mm}$.) or dust persists, defined by some authors as clinically insignificant residual fragments. ${ }^{3-7}$ Such fragments are found at the renal level in $85 \%$ of patients at discharge after extracorporeal treatment, and are considered a factor that favors progression of lithiasis, ${ }^{8.9}$ and an increased risk for significant symptomatic episodes or need for intervention. ${ }^{10}$ We describe a select group of asymptomatic patients with fragments and dust 3 months after extracorporeal treatment, who were followed to evaluate the long-term outcome and therapeutic implications.

\section{PATIENTS AND METHODS}

For this study we considered 467 patients who underwent treatment with Dornier HM3 modified and MPL 9000 lithotriptors for a single radiopaque renal stone $15 \mathrm{~mm}$. or less between 1991 and 1994. Other selection criteria were the absence of morphological alterations of the urinary system as shown on pretreatment excretory urography and ultrasonography, no previous urinary tract surgery, no history of infection stones and negative urine culture before treatment. Patients with definite metabolic disease, such as hyperparathyroidism and renal tubular acidosis, were also excluded. Thus, we considered only patients with simple renal lithiasis in the presence of normal renal morphology and function.

Accepted for publication February 28, 1997.
Three months after treatment the patients were assessed on the basis of a plain abdominal x-ray (including renal tomography), renal ultrasonography and urine culture, which revealed that $299(64 \%)$ were stone-free, whereas $27(6 \%)$ had residual fragments greater than $4 \mathrm{~mm}$. or more and were sent for further treatment. These 2 groups of patients were excluded from the study. The remaining 141 patients presented with dust (shown radiologically to be uniformly distributed in the calices, 87 cases, $62 \%$ ) or single residual fragments of overall diameter of $4 \mathrm{~mm}$. or less ( 54 patients, $38 \%$ ). Urine culture was positive in 12 patients despite the initial selection which excluded subjects with positive urine culture or a history of infection stones. All 12 patients received full doses of appropriate antibiotics but 7 still had a positive urine culture at the 12-month examination. Calcium oxalate and calcium phosphate were identified in these stones and urine colture did not reveal any urea-splitting bacterium, except Escherichia coli in 7 cases, Enterococcus in 4 and Enterobacter in 1.

A total of 69 women and 60 men, 19 to 80 years old (mean age plus or minus standard deviation $49.4 \pm 13.0$ ), with dust and residual fragments at 3 months were reexamined at 12 months, whereas 12 were lost to followup and 95 were also evaluated at 24 months. Of the 129 patients studied 46 $(35.6 \%)$ had a history of stone with a stone relapse per year per patient index less than 0.2 with 60 previous stones. For this reason we considered our study population at a low risk for stone recurrence.

Followup examinations consisted of radiographic studies, renal ultrasonography and urine culture. Dust and residual fragments were sought, and patients were defined as free or as having persistent lithiasis or stone regrowth (regrowth has been defined as any fragment size increment radiographically evaluated at 12 and 24-month followup). At 24 months 
recurrences in the patients stone-free at 12 months also were considered. In addition, we investigated the possibility that clearance of fragments could be correlated with localization of the stone before treatment or of the fragments 3 months after treatment, the size of the stone, the presence of dust or residual fragments and the occurrence of symptomatic episodes related to residual stones. The chi-square contingency table was used for statistical analysis.

\section{RESULTS}

The localization of the stones was pyelic in 34 of the 129 patients $(26.4 \%)$ who underwent the 12 -month examination, upper caliceal in $16(12.4 \%)$, mid caliceal in $17(13.2 \%)$ and lower caliceal in $62(48 \%)$. The maximum diameter of the treated stones varied from 5 to $15 \mathrm{~mm}$. (mean $9.4 \pm 3.2$ ). The localization of the fragments and dust 3 months after shock wave lithotripsy was upper caliceal in 10 patients $(7.7 \%)$, mid caliceal in $34(26.3 \%)$ and lower caliceal in $85(66 \%)$ (table 1$)$. At the 12-month followup 60 patients $(46.5 \%)$ were stone-free and $56(43.5 \%)$ still presented with dust or residual fragments. The initial stone localization from which fragments were most readily eliminated was the pelvis $(67.6 \%$ of patients became stone-free), followed by the upper, lower and mid calix (stone-free rates of $56,37.1$ and $29.4 \%$, respectively) (table 2). Considering instead the localization of fragments or dust 3 months after treatment, 70,59 and $39 \%$ of patients with upper, mid and lower caliceal lithiasis became stonefree, respectively (table 3 ). The localization of the stones or fragments at 3 months and their sizes did not have a significant influence on the stone-free rate but regrowth was greater in patients with stones larger than $10 \mathrm{~mm}$. (11 of 40 patients, $27.5 \%$ versus 2 of $89,2.2 \%, p=0.001$, table 4). Fragment regrowth at 12 -month followup did not show any significant difference between the group with or without history of stones. In the former group regrowth rate was $13 \%$ ( 6 of 46 patients) while in the latter it was $8.4 \%$ (7 of 83 patients) $(p=0.27)$. The probability of eliminating residual lithiasis at 12 months was significantly greater in patients with dust than in those with residual fragments (42 of 79 patients, $58 \%$ versus 18 of $50,36 \%, p=0.026$ ) (table 5 ).

Regrowth of residual lithiasis was observed in the lower calix in 12 cases and in the mid calix in 1 , including 8 in which the initial localization of the stone was lower caliceal. Five patients had a positive urine culture at 3 and 12 months. Of the remaining patients with a positive urine culture at 3 months 7 were stone-free at 12 months, including 5 with a negative and 2 with a positive urine culture. Eight patients $(6.2 \%)$ with stone regrowth underwent further shock wave lithotripsy, including 4 with symptoms, 3 with a positive urine culture and 1 with a dilated calix due to obstruction of the caliceal neck. Only 2 patients (25\%) became completely stone-free, including 1 with a positive urine culture that became negative. In the other cases the stone mass was reduced and the symptoms improved or resolved.

Of the 129 patients 95 were available for followup 2 years after treatment, including $54(56.8 \%)$ with residual lithiasis at 12 months, and 34 were lost to followup, including 15 with residual lithiasis, 18 stone-free and 1 with regrowth. At 2

TABLE 1. Localization of fragments and pre-lithotripsy stones

\begin{tabular}{|c|c|c|c|c|c|}
\hline \multirow{2}{*}{$\begin{array}{l}\text { Fragment } \\
\text { Localization }\end{array}$} & \multicolumn{4}{|c|}{ Pre-lithotripsy Stones } & \multirow{2}{*}{$\begin{array}{c}\text { Total No. } \\
(\%)\end{array}$} \\
\hline & Pelvis & $\begin{array}{l}\text { Upper } \\
\text { Calix }\end{array}$ & $\begin{array}{c}\text { Middle } \\
\text { Calix }\end{array}$ & $\begin{array}{l}\text { Lower } \\
\text { Calix }\end{array}$ & \\
\hline $\begin{array}{l}\text { Upper calix } \\
\text { Mid calix } \\
\text { Lower calix }\end{array}$ & $\begin{array}{r}3 \\
16 \\
15 \\
\end{array}$ & $\begin{array}{l}7 \\
4 \\
5 \\
\end{array}$ & $\begin{array}{r}14 \\
3 \\
\end{array}$ & $62^{-}$ & $\begin{array}{rr}10 & (7.7) \\
34 & (26.3) \\
85 \quad(66) \\
\end{array}$ \\
\hline $\begin{array}{l}\text { Total No. } \\
(\%)\end{array}$ & $34(26.4)$ & $16(12.4)$ & $17(13.2)$ & $62(48)$ & $129(100)$ \\
\hline
\end{tabular}

TABLE 2. 12-Month followup results according to pretreatment stone localization

\begin{tabular}{|c|c|c|c|c|}
\hline $\begin{array}{c}\text { Stone } \\
\text { Localization }\end{array}$ & $\begin{array}{l}\text { No. } \\
\text { Stone-Free } \\
\text { (\%) }\end{array}$ & $\begin{array}{l}\text { No. Unchanged } \\
\text { Fragments (\%) }\end{array}$ & $\begin{array}{l}\text { No. } \\
\text { Regrowth } \\
\text { (\%) }\end{array}$ & $\begin{array}{c}\text { Total No. } \\
\text { (F) }\end{array}$ \\
\hline $\begin{array}{l}\text { Upper calix } \\
\text { Mid calix } \\
\text { Lower calix } \\
\text { Pelvis }\end{array}$ & $\begin{array}{r}9(56.3) \\
5(29.4) \\
23(37.1) \\
23(67.6)\end{array}$ & $\begin{array}{r}5(31.3) \\
11(64.7) \\
31 \quad(50) \\
9(26.5) \\
\end{array}$ & $\begin{array}{lr}2 & (12.6) \\
1 & (5.9) \\
8(12.9) \\
2 \quad(5.8) \\
\end{array}$ & $\begin{array}{l}16(12.4) \\
17(13.2) \\
62(48.1) \\
34(26.4) \\
\end{array}$ \\
\hline $\begin{array}{l}\text { Total No. } \\
\text { (\%) }\end{array}$ & $60(46.5)$ & $56(43.5)$ & $13 \quad(10)$ & $129(100)$ \\
\hline
\end{tabular}

TABLE 3. 12-Month followup results according to fragment localization

\begin{tabular}{lccc}
$\begin{array}{c}\text { Fragment } \\
\text { Localization }\end{array}$ & $\begin{array}{c}\text { No. Stone-Free } \\
(\%)\end{array}$ & $\begin{array}{c}\text { No. Unchanged } \\
\text { Fragments }(\%)\end{array}$ & $\begin{array}{c}\text { No. Regrowth } \\
(\%)\end{array}$ \\
\hline Upper calix & $7(70)$ & $3(30)$ & - \\
Mid calix & $20(58.8)$ & $13(38.2)$ & 1 \\
Lower calix & $\underline{33(38.8)}$ & $\underline{40(47)}$ & $\underline{12(14.11)}$ \\
Total No. $(\%)$ & $60(46.5)$ & $56(43.5)$ & $13 \quad(10)$ \\
\hline
\end{tabular}

TABLE 4. 12-Month followup results according to pretreatment stone size

\begin{tabular}{ccccc}
\hline $\begin{array}{c}\text { Stone Size } \\
\text { (mm.) }\end{array}$ & $\begin{array}{c}\text { No. Unchanged } \\
\text { Fragments (\%) }\end{array}$ & $\begin{array}{c}\text { No. Regrowth } \\
(\%)\end{array}$ & $\begin{array}{c}\text { No. Stone-Free } \\
(\%)\end{array}$ & $\begin{array}{c}\text { Total No. } \\
(\%)\end{array}$ \\
\hline 5 or Less & $6(43)$ & - & $8(67)$ & $14(11)$ \\
$6-10$ & $41(54.6)$ & $2(2.7)$ & $32(42.7)$ & $75(58)$ \\
$11-15$ & $\underline{9(22.5)}$ & $\underline{11(27.5)^{*}}$ & $\underline{20(50)}$ & $\underline{40(31)}$ \\
Total No. (\%) & $\mathbf{5 6 ( 4 3 . 5 )}$ & $13(10)$ & $60(46.5)$ & $129(100)$ \\
\hline
\end{tabular}

${ }^{*} \mathrm{p}=0.001$.

TABLE 5. 12-Month followup results according to the presence of dust or residual fragments

\begin{tabular}{lccccc}
\hline & $\begin{array}{c}\text { No. Stone-Free } \\
(\%)\end{array}$ & $\begin{array}{c}\text { No. Unchanged } \\
\text { Fragments }(\%)\end{array}$ & $\begin{array}{c}\text { No. Regrowth } \\
(\%)\end{array}$ & $\begin{array}{c}\text { Total No. } \\
(\%)\end{array}$ \\
\hline Dust & $42(53.2)^{*}$ & $32(40.5)$ & $5(6.3)$ & $79(61.2)$ \\
Fragments & $\underline{18(36)}$ & $\underline{24(48)}$ & $\underline{8(16)}$ & $50(38.8)$ \\
$\begin{array}{l}\text { Total No. }(\%) \\
{ }^{*} p=0.026 .\end{array}$ & $60(46.6)$ & $56(43.3)$ & $13(10)$ & $129(100)$ \\
\hline
\end{tabular}

years 11 more patients were stone-free, increasing the overall number in whom fragments were eliminated to 71 (55\% of the subgroup with fragments at 3 months). Regrowth of fragments was observed in 5 other patients $(5.2 \%)$. Two patients $(2.1 \%)$ with stone regrowth at 12 months that was not treated presented with increased regrowth, whereas regrowth in 2 others remained unchanged. Two patients stonefree at 12 months had recurrence at 24 months. Of the 8 patients who underwent further shock wave lithotripsy 2 were stone-free and 6 had residual fragments at the 24month examination (table 6). A total of 15 patients (11.6\%) had symptoms, colic or low back pain, in the first year of followup. Overall, $14.7 \%$ of the patients had symptomatic events or required further treatment in the first year of followup. In the second year of followup $7.3 \%$ of patients (7) manifested pain symptoms.

\section{DISCUSSION}

Residual fragments represent a common and still controversial problem of extracorporeal treatment. Although efficacious fracture of stones into fragments less than $5 \mathrm{~mm}$. has been described in $85 \%^{11}$ and $96 \%$ of cases, 3 months after extracorporeal treatment residual fragments were present in 24 to $36 \% .^{3,11,12}$ Asymptomatic fragments less than 4 or 5 $\mathrm{mm}$. not associated with infection were initially defined as clinically insignificant residual fragments. Regrowth of frag- 
TABLE 6. 2-Year followup results

\begin{tabular}{|c|c|c|c|c|c|}
\hline $\begin{array}{l}\text { Fragments and Dust } \\
\text { Localization }\end{array}$ & $\begin{array}{c}\text { No. Stone-Free } \\
(\%)\end{array}$ & $\begin{array}{l}\text { No. Unchanged } \\
\text { Fragments }(\%)\end{array}$ & $\begin{array}{l}\text { No. Regrowth } \\
(\%)\end{array}$ & $\begin{array}{c}\text { No. Recurrence } \\
(\%)\end{array}$ & $\begin{array}{c}\text { Total No. } \\
(\%)\end{array}$ \\
\hline $\begin{array}{l}\text { Upper calix } \\
\text { Mid calix } \\
\text { Lower calix }\end{array}$ & $\begin{array}{rr}8 & (89) \\
22 & (75) \\
23 & (40.4) \\
\end{array}$ & $\begin{array}{r}1(11) \\
4(13.8) \\
28(49.1) \\
\end{array}$ & $\begin{array}{ll}2 & (7) \\
5(8.8) \\
\end{array}$ & $\begin{array}{l}1(3.4) \\
1(1.7) \\
\end{array}$ & $\begin{array}{rr}9 & (9) \\
29 & (31) \\
57 & (60) \\
\end{array}$ \\
\hline Total No. $\left|C_{x}\right|$ & $53(55.8)$ & $33(34.8)$ & $7(7.3)$ & $2(2.1)$ & $95(100)$ \\
\hline
\end{tabular}

ments less than $4 \mathrm{~mm}$. was reported by Newman et al in $21.7 \%$ of their series at 1 year. ${ }^{13} \mathrm{Yu}$ et al found an overall stone regrowth rate of $26 \%$ after a mean followup of 75 months, and the regrowth of fragments correlated significantly with the size, site and multiplicity of stones. ${ }^{14}$ In a previous study of 247 patients we observed fragments less than $4 \mathrm{~mm}$. in $36.6 \%$ of patients at 3 months, with a higher regrowth rate in patients treated for multiple, pyelocaliceal and lower caliceal stones. ${ }^{12}$ In these unselected series the regrowth of residual fragments present at 3 months was $70 \%{ }^{14}$ and $64 \%,{ }^{12}$ respectively, at long-term followup. Beck and Riehle reported that $47 \%$ of their patients treated with shock wave lithotripsy for infection stones was stone-free after a mean followup of 26.6 months, and $78 \%$ with fragments greater than $5 \mathrm{~mm}$. and $48 \%$ with dust or fragments less than $4 \mathrm{~mm}$. presented with disease progression in the long term. ${ }^{8}$

With the aim of improving the clearance of residual fragments various authors $5.15,16$ have proposed early retreatment, with complete elimination of stones or improvement in $40 \%$ and $83 \%^{16}$ of the patients, but the systematic re-treatment of all asymptomatic patients was not justified by Newman et al. ${ }^{13}$ On the other hand, Moon and Kim observed that re-treatment of even small fragments with a piezoelectric lithotriptor 1 month after the first treatment eliminated residual fragments in $92 \%$ of patients at 6 months of followup. ${ }^{7}$ Cicerello et al demonstrated that the administration of citrates resulted in clearance of residual fragments at 12 months, increasing the stone-free rates from 32 to $74 \%$ in cases of sterile calcium oxalate stones and from 40 to $86 \%$ for infection stones. ${ }^{17}$ They also reported that clearance in patients with residual infection stone fragments may be improved by adequate chemotherapy. Fine et al suggested that appropriate medical treatment may be efficacious in the prophylaxis of recurrences and in reducing the proportion of patients with regrowth of residual fragments less than $5 \mathrm{~mm}$. to $16 \% .9$ More recently, based on a prospective study of 160 patients who presented with dust or residual fragments less than $4 \mathrm{~mm}$., Streem et al consider that the description "clinically insignificant ${ }^{n}$ applied to any residual stone after shock wave lithotripsy is likely a misnomer. ${ }^{10}$ In fact, $43 \%$ of the examined patients had symptomatic episodes or required intervention at a mean followup of 26 months. In the same period $23.8 \%$ of the patients became stone-free and $18 \%$ manifested fragment regrowth.

In our select group of patients spontaneous elimination of fragments, particularly dust, was good at 12-month followup $(46.5 \%)$. This rate, better than in other series including our own may be attributable to the selection of single stones less than $15 \mathrm{~mm}$. with normal renal morphology. At 24-month followup only a further $8.5 \%$ of the patients became stonefree. On the other hand, symptomatic episodes occurred in about $19 \%$ of the patients by the 2 -year followup, for a total of $22 \%$ of patients who had symptoms or required retreatment. The decision to include patients in the study 3 months after treatment probably decreased the proportion of symptomatic episodes and interventions due to the elimination of most stones in the first months. Fragment regrowth was observed in $17 \%$ of the patients, particularly those who had pretreatment stones greater than $10 \mathrm{~mm}$. and those who still had a positive urine culture at 12 months. No urea- splitting germ was isolated in the latter group of patients and regrowth could not be attributed, in our opinion, to struvite deposition. On the other hand, urine stasis due to obstructing fragments, even if without gross urinary dilatation, can promote infection and regrowth. The greater probabilities of regrowth of residual fragments are correlated in the literature with the presence of infection stones, stone size and multiple stones. At present, however, the majority of stones treated at lithotripsy centers are less than $15 \mathrm{~mm}$. about $80 \%$ of our cases, and mean stone size has decreased during the years.

Our patients belong to a low recurrence risk population, and since a definite metabolic disease (hyperparathyroidism or tubular acidosis) was excluded at enrollment into the study, we did not perform a complete metabolic evaluation. We cannot definitively exclude an idiopathic metabolic disease for which pharmacological therapy could be indicated to lower the relapse index or fragment regrowth ${ }^{9}$ but a high fluid intake regimen was recommended for every patient during followup.

\section{CONCLUSIONS}

Patients with fragments, like those included in our study, were stone-free within the first year after shock wave lithotripsy but the stone-free rate was lower in the second year. Such patients may not require systematic re-treatment in the short term but in the long term re-treatment may be necessary if symptoms persist or stones recur.

\section{REFERENCES}

1. Chaussy, C.: ESWL: Past, Present, Future. J. Endourol., 2: 97, 1988.

2. Chaussy, C., Schmiedt, E., Jocham, D., Brendel, W., Forsmann, B. and Walther, V.: First clinical experience with extracorporeally induced destruction of stones by shock waves. J. Urol., 127: 417,1982 .

3. Lingeman, J. E., Newman, D., Mertz, J. H., Mosbaugh, P. G., Steele, R. E., Kahnoski, R. J., Coury, T. A. and Woods, J. R.: Extracorporeal shock wave lithotripsy: Methodist Hospital of Indiana experience. J. Urol., 135: 1134, 1986.

4. Liedle, B., Jocham, D., Lunz, C., Schuster, C. and Schmiedt, E.: Five-year follow-up of urinary stone patients treated with extracorporeal shock wave lithotripsy. J. Endourol., 2: 157, 1988.

5. Parr, N. J., Ritchie, A. W., Smith, G., Moussa, S. A. and Tolley, D. A.: Does further extracorporeal lithotripsy promote clearance of small residual fragments? Brit. J. Urol., 68: 565, 1991.

6. Rassweiler, J., Kohrmann, K. U. and Alken, P.: ESWL, including imaging. Curr. Opin. Urol., 2: 291, 1992.

7. Moon, Y. T. and Kim, S. C.: Fate of clinically insignificant residual fragments after extracorporeal shock wave lithotripsy with EDAP LT-01 lithotripter. J. Endourol., 7: 453, 1993.

8. Beck, E. M. and Riehle, R. A., Jr.: The fate of residual fragments after extracorporeal shock wave lithotripsy monotheraphy of infection stones. J. Urol., 145: 6, 1991.

9. Fine, J. K., Pak, C. Y. C. and Preminger, G. M.: Effect of medical management and residual fragments on recurrent stone formation following shock wave lithotripsy. J. Urol., 153: 27, 1995.

10. Streem, S. B., Jost, A. and Mascha, E.: Clinical implication of clinically insignificant stone fragments after extracorporeal shock wave lithotripsy. J. Urol., 155: 1186, 1996.

11. Drach, G. W., Dretler, S., Fair, W., Finlayson, B., Gillenwater, J., 
Griffith, D., Lingeman, J. and Newman, D.: Report of the United States cooperative study of extracorporeal shock wave lithotripsy. J. Urol., 135: 1127, 1986.

12. Zanetti, G., Montanari, E., Mandressi, A., Guarneri, A., Ceresoli, A., Mazza, L., Trinchieri, A. and Pisani, E.: Long-term results of extracorporeal shock wave lithotripsy in renal stone treatment. J. Endourol., 5: 61, 1991.

13. Newman, D. M., Scott, J. W. and Lingeman, J. E.: Two-year follow-up of patients treated with extracorporeal shock wave lithotripsy. J. Endourol., 2: 163, 1988.

14. Yu, C. C., Lee, Y. H., Huang, J. K., Chen, M. T., Chenk, K. K., Lin, A. T. and Chang, L. S.: Long-term stone regrowth and recurrence rates after extracorporeal shock wave lithotripsy. Brit. J. Urol., 72: 688, 1993.

15. Liedle, B., Jocham, D., Schuster, C. and Lunz, C.: Long term results in ESWL-treated urinary stone patients. Urol. Res., 16: $256,1988$.

16. Krings, F., Tuerk, C. H., Steinkogler, I. and Marberger, M.: Extracorporeal shock wave lithotripsy retreatment ("stir-up") promotes discharge of persistent caliceal stone fragments after primary extracorporeal shock wave lithotripsy. J. Urol., 148: 1040,1992

17. Cicerello, E., Merlo, F., Gambaro, G., Maccatrozzo, L., Fandella, A., Baggio, B. and Anselmo, G.: Effects of alkaline citrate therapy on clearance of residual renal stone fragments after extracorporeal shock wave lithotripsy in sterile calcium and infection nephrolothiasis patients. J. Urol., 151: 5, 1994.

\section{EDITORIAL COMMENT}

This study of a highly selected group of patients with post-shock wave lithotripsy stone fragments addresses an area of current controversy regarding the clinical significance of residual stone, and the need for secondary prophylactic intervention. The authors followed
129 patients with stone fragments at 3 months for another 1 to 2 years to determine rates of symptomatic episodes, stone growth and stone recurrence. Inclusion in this study required treatment to a solitary stone measuring less than $1.5 \mathrm{~cm}$. Patients with known metabolic disorders were specifically excluded. Results were stratified for initial stone burden and location, as well as for size and location of the residual fragments.

Of patients with residual fragments at 3 months posttreatment $46.5 \%$ and $55 \%$ became stone-free after 1 and 2 years, respectively. Stone regrowth, while not well defined, was noted in $13 \%$ and $5 \%$ of patients at 1 and 2 years, respectively, and $21 \%$ had symptomatic episodes or required intervention during that time. The authors conclude that while patients such as these with residual post-shock wave lithotripsy fragments do not require "systematic re-treatment," careful followup and subsequent medical therapy or urological intervention may be required.

Their conclusions should be placed in perspective for this highly select group of patients. The study group was limited to patients with a solitary stone at the time of treatment, and patients with known metabolic disorders were excluded. As such, it is likely that rates of stone regrowth and recurrence, as well as symptomatic episodes or need for intervention, would have been higher had these patients been more representative of a general stone population. However, it is also likely that the addition of medical therapy would impact positively on these results. Overall, this study appears to reinforce a growing consensus that, while any post-shock wave lithotripsy residual stone may in fact become symptomatic, secondary more invasive intervention is generally not warranted prophylactically.

Stevan B. Streem

Department of Urology

Cleveland Clinic Foundation

Cleveland, Ohio 